\title{
Permeability of rat ovarian follicles to LH during development and luteinization
}

\author{
R. S. Carson, L. A. Salamonsen and J. K. Findlay \\ Medical Research Centre, Prince Henry's Hospital, St Kilda Road, Melbourne, Victoria 3004, \\ Australia
}

\begin{abstract}
Summary. A 'double isotope' technique has been used to describe the temporal relationship between plasma and follicular concentrations of $\mathrm{LH}$ after injection of ${ }^{51} \mathrm{Cr}$ and ${ }^{125} \mathrm{I}$-rat $\mathrm{LH}$ into immature rats. Radiolabelled $\mathrm{LH}$ was detectable in all follicles 1 min after injection. Concentrations in small antral and large preovulatory follicles were not significantly different at any time and reached a maximum of $34 \cdot 2 \pm 3.0 \%$ of plasma concentrations at $40 \mathrm{~min}$. Concentrations of $\mathrm{LH}$ in preovulatory follicles exposed to an ovulatory dose of hCG $4 \mathrm{~h}$ previously were significantly greater $(P<0.05)$ than those in small antral and preovulatory follicles at all times, and reached a maximum of $46 \cdot 2 \pm 1 \cdot 7 \%$ of plasma concentrations after $1 \mathrm{~h}$. Polyacrylamide gel electrophoresis and immunoprecipitation with an antibody specific for rat $\mathrm{LH}$ indicated that radioactivity in plasma and follicular fluid represented radio-iodinated L.H. Steroidogenic activities, light microscopy and measurements of follicular volume of each class of follicle confirmed that small antral, preovulatory follicles and preovulatory follicles exposed to an ovulatory dose of $\mathrm{hCG}$ in vivo could be isolated specifically.

Based on these findings it is possible to calculate that, during an endogenous pulse of LH secretion, follicular concentrations of $\mathrm{LH}$ never exceed $20 \%$ of peak plasma concentrations. Pronounced increases in functional activities during antral growth were not correlated with increased follicular permeability. Only after acute exposure to an ovulatory dose of hCG in vivo was permeability significantly increased. We conclude that entry of $\mathrm{LH}$ into antral follicles is restricted and that exposure to an ovulatory dose of hCG results in greater amounts of $\mathrm{LH}$ entering preovulatory follicles.
\end{abstract}

\section{Introduction}

Development and luteinization of ovarian follicles is dependent primarily upon the interaction of pituitary luteinizing hormone ( $\mathrm{LH})$ and follicle-stimulating hormone (FSH) with thecae and granulosa cells (Lindner et al., 1977; Richards 1979). In contrast to the cells of the theca which lie close to the follicular blood supply, granulosa cells exist in an avascular environment within the follicular antrum. Any substance reaching granulosa cells from the peripheral circulation must therefore traverse the capillary wall, interspersed theca cells, and the follicular basement membrane.

Because FSH and particularly LH are secreted by the pituitary in a pulsatile manner (Gallo, 1981a, b; Goodman \& Daniel, 1985), the intrafollicular concentration attained before the eventual decay of each pulse of gonadotrophin is uncertain. We have used a 'double isotope' technique to describe the temporal relationship between plasma and intrafollicular concentrations of LH during an exogenous pulse of radiolabelled hormone into immature rats. Small antral and large antral (preovulatory) follicles and follicles exposed to ovulatory levels of $\mathrm{LH}$ activity have been studied. 


\section{Materials and Methods}

Animals. Female Sprague-Dawley rats were obtained at 24 days of age, maintained under controlled lighting conditions thereafter ( $14 \mathrm{~h}$ dark, $10 \mathrm{~h}$ light) and allowed free access to solid food and water.

Treatment with hCG. Animals were treated s.c. with hCG (Pregnyl, Organon Laboratories, Artarmon, N.S.W.) in $200 \mu \mathrm{l}$ phosphate-buffered saline (PBS; 0.05 $\mathrm{M}_{-} \mathrm{PO}_{4}, 0.154 \mathrm{M}-\mathrm{NaCl}$ ) at $12-\mathrm{h}$ intervals starting at $08: 00 \mathrm{~h}$ on Day 28 of age. At 10:00 h on Day 30 of age, small antral follicles were isolated from untreated animals, and large preovulatory follicles from animals treated with 0.5 i.u.hCG. Large preovulatory follicles were also isolated from hCG-treated animals which received an additional intravenous injection of an ovulatory dose of hCG (10 i.u.) at 06:00 h on Day 30.

Radioisotopes. Carrier-free sodium iodide $\left({ }^{125} \mathrm{I}\right.$; Amersham, Sydney, N.S.W.), radiolabelled sodium chromate $\left({ }^{51} \mathrm{Cr} ; 250-500 \mathrm{mCi} / \mathrm{mg}\right.$; Amersham), $16 \alpha$-iodo-3,17 $\beta$-oestradiol $\left[{ }^{125} \mathrm{I}\right](1850 \mathrm{Ci} /$ mmol: New England Nuclear, Boston, MA, U.S.A.) and $11 \alpha$-iodo-progesterone $\left[{ }^{125} \mathrm{I}\right]$ (Radioassay Systems Lab, Carson, CA, U.S.A.) were obtained commercially. Radioiodinated rat LH (rLH-5, NIAMDD) was prepared using a solid-phase iodogen (Fraker \& Speck, 1978). Rat LH, $4 \mu \mathrm{g}$ in $20 \mu \mathrm{l}$ phosphate-buffered saline (PBS; $0.145 \mathrm{M}-\mathrm{NaCl}, 0.1 \mathrm{M}$-phosphate, $\mathrm{pH} 7 \cdot 2$ ), was reacted with $1.0 \mathrm{mCi}$ carrier-free ${ }^{125} \mathrm{I}$ in a polypropylene tube coated with $32 \mu \mathrm{g}$ iodogen $(1,3,4,6$-tetrachloro$3,6 \alpha$-diphenyl glycolurocil). After reaction at room temperature for $10 \mathrm{~min}$, the reaction products were resolved by gel chromatography (Biogel P60, $20 \times 1 \mathrm{~cm}$ in $0.1 \%$ BSA. PBS). Specific activityof ${ }^{125} \mathrm{I}$-labelled rat $\mathrm{LH}$ prepared in this manner was $160-180 \mu \mathrm{Ci} / \mu \mathrm{g}$ as determined by ratios of areas under peaks in each elution profile.

Steroid production by follicles in vitro. Individual follicles were dissected from surrounding ovarian tissue as previously described (Carson, Richards \& Kahn, 1981). Small antral and preovulatory follicles and preovulatory follicles exposed to an ovulatory dose of hCG in vivo were incubated in $500 \mu \mathrm{l}$ Medium 199 (Flow Laboratories, Sydney, N.S.W.; $10 \mathrm{mm-Hepes,} \mathrm{pH} \mathrm{7.4)} \mathrm{at}$ $37^{\circ} \mathrm{C}$ for $4 \mathrm{~h}$ under an atmosphere of $5 \% \mathrm{CO}_{2}$ in oxygen. Incubation was terminated by rapid freezing. Progesterone and total oestrogen were measured directly in cell-free incubation media. When added to incubation tubes immediately before freezing, recovery of ${ }^{3} \mathrm{H}$-labelled progesterone and oestradiol $-17 \beta$ from incubation media was greater than $97 \%$.

Radioimmunoassay of steroids. Total oestrogens in incubation media were measured using an antiserum raised against oestradiol-17 $\beta-6-\mathrm{CMO}-\mathrm{BSA}$ and $16 \alpha$-iodo-3,17 $\beta$-oestradiol $\left[{ }^{125} 1\right]$ (New England Nuclear) as the labelled ligand. A standard preparation of unlabelled oestradiol-17 $\beta$ or known volume of incubation medium was added to a total volume of $500 \mu$ l. After addition of tracer $(20000$ c.p.m. in $100 \mu \mathrm{l})$ and antiserum $(200 \mu \mathrm{l})$ all tubes were incubated overnight at $4{ }^{\circ} \mathrm{C}$.

Fig. 1. Ovaries were isolated from 3 immature rats in each treatment group and the micrographs are representative of the specimens obtained. $\times 37$.

(a) Untreated animal, Day 28 of age, showing many preantral and small antral follicles.

(b) Untreated animal, Day 30 of age.

(c) Day 30 of age after injection of hCG (0.5 i.u.) in the morning and evening of Days 28 and 29.

Each ovary contained 4-6 large antral follicles in addition to many small antral and preantral follicles.

(d) Day 30 of age after treatment with hCG (0.5 i.u.) for 2 days and subsequently with 10 i.u. (i.v.) $4 \mathrm{~h}$ before isolation of tissue. 


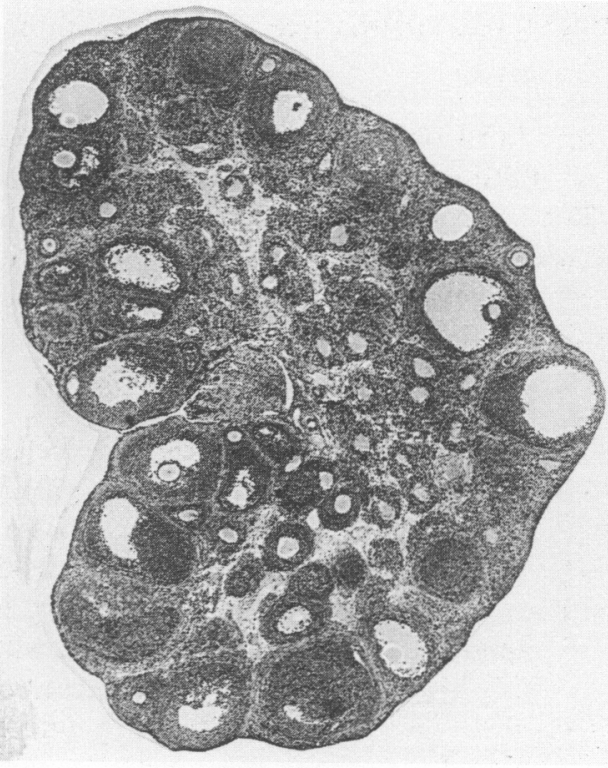

(a)
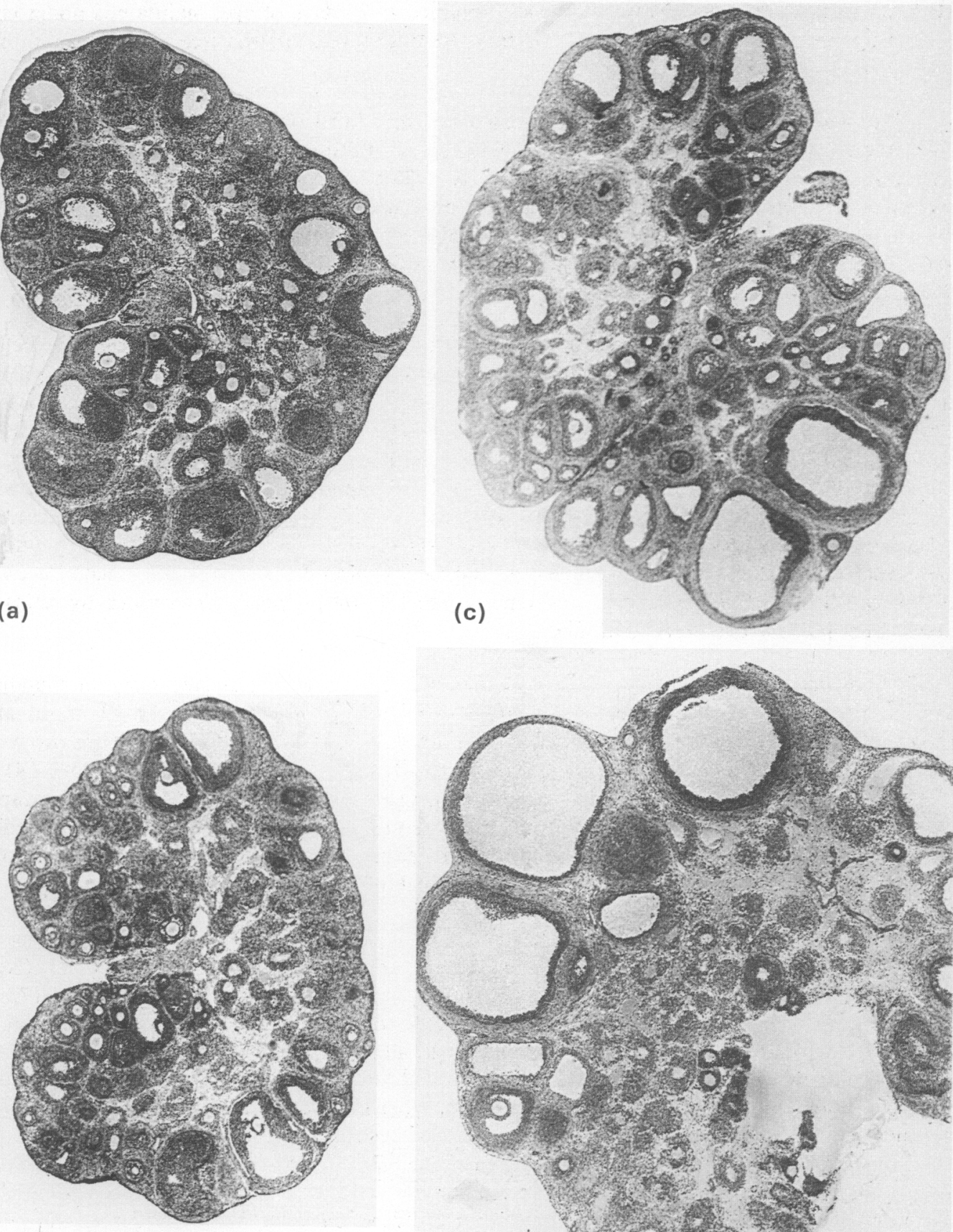

(b)

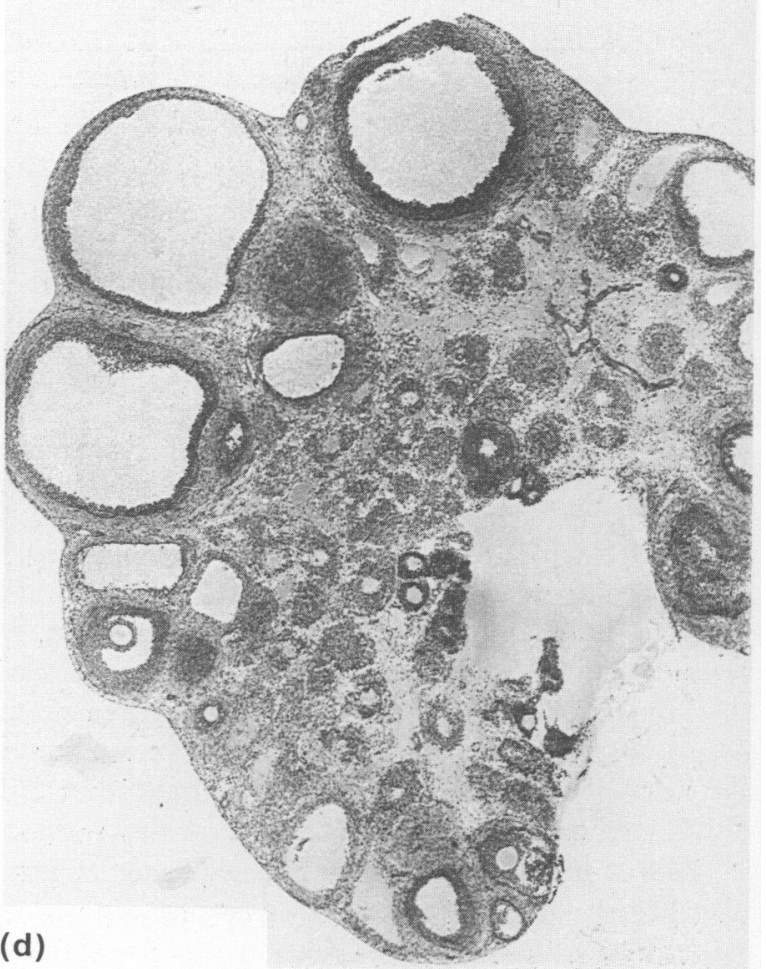



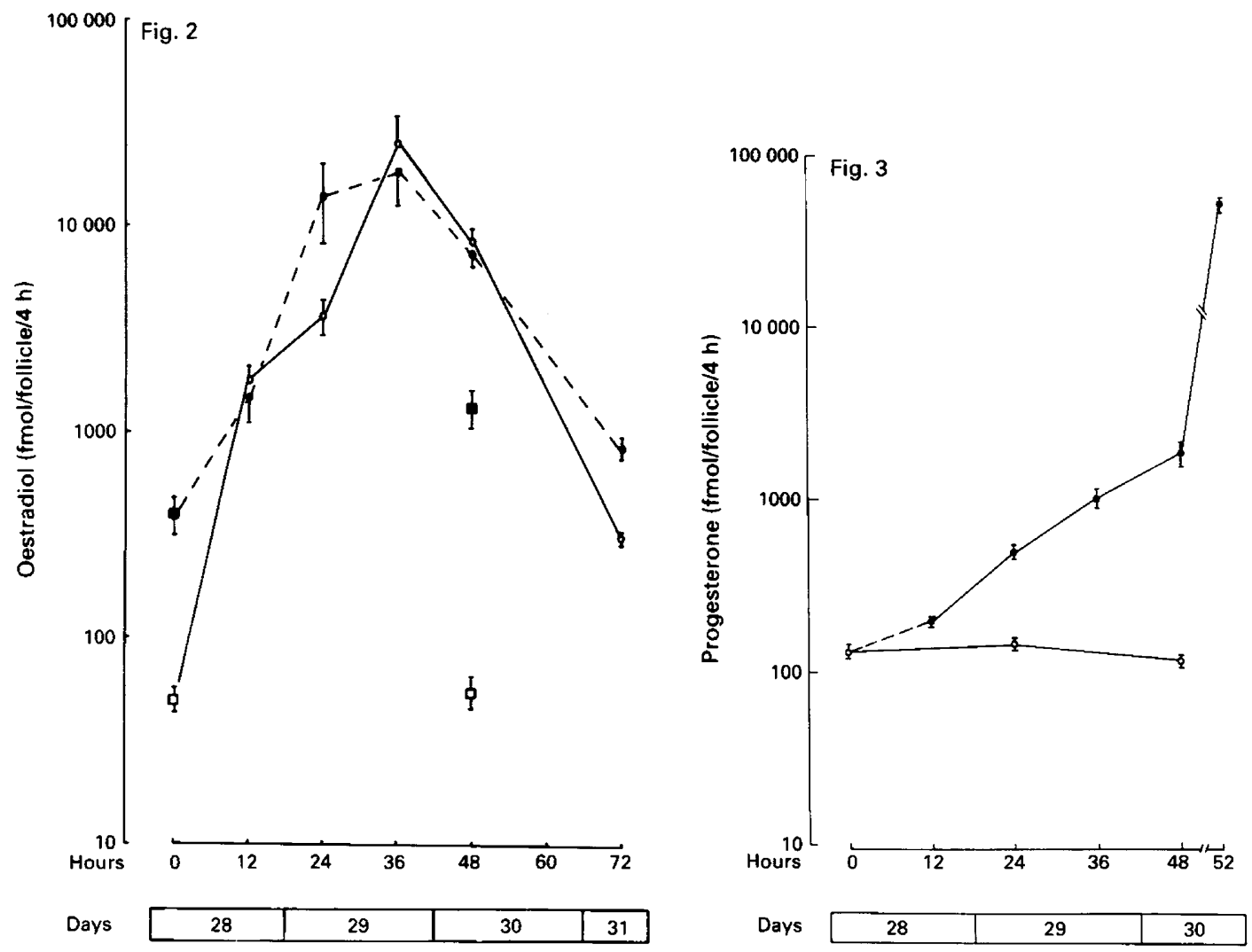

Fig. 2. Time-course of response of follicles to hCG in vivo as measured by production of oestradiol in vitro. Follicles were isolated from untreated animals at Days 28 and $30(0$ \& $48 \mathrm{~h}$;

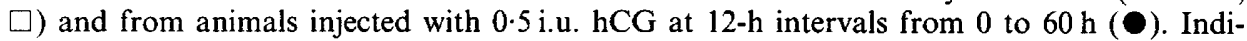
vidual follicles were incubated in medium alone $(\square O ; n=5)$ or in the presence of exogenous testosterone (150 nM; $\boldsymbol{0} ; n=15)$. Values represent mean \pm s.e.m.

Fig. 3. Progesterone production by rat ovarian follicles in vitro after treatment with hCG in vivo. Follicles were isolated from untreated animals at Days 28,29 and $30(O)$ and from animals injected with $0.5 \mathrm{i}$.u. hCG at $0-36 \mathrm{~h}$ and given $10 \mathrm{i}$.u. intravenously at $48 \mathrm{~h}(\bullet)$. Values represent the mean \pm s.e.m. of 20 individual follicles.

Charcoal $(1.0 \mathrm{ml}, 0 \cdot 2 \%(\mathrm{w} / \mathrm{v})$ Dextran $\mathrm{T} 70)$ was added, tubes centrifuged and radioactivity in the antibody-bound fraction (supernatant) determined. When calculated as the quotient of the mass of steroid required for $50 \%$ displacement of radiolabelled oestrogens, cross-reactivity of oestrone and oestriol were each $100 \%$ and that of androstenedione $0.3 \%$. Cross-reactivity of a range of other androgens, progestagens and corticoids were otherwise $<0.1 \%$. Based on 10 consecutive assays, the limit of detection was $2 \pm 1 \mathrm{fmol}$ oestradiol-17 $\beta /$ tube, variance was $<15 \%$ over the range 6-127 fmol oestrogen/tube and between-assay variance was $12 \cdot 1 \%$.

RIA of progesterone was performed using reagents supplied under World Health Organisation Matched Reagents Program and in accordance with WHO recommendations. Based on 10 consecutive assays, the limit of detection was $9 \pm 2 \mathrm{fmol} /$ tube, variance was $<15 \%$ over the range 64-1046 fmol/tube and between-assay variance was $7 \cdot 1 \%$.

Assays were performed directly on cell-free incubation media without prior extraction with 
solvents and data were processed using a computer program based on the method of Burger, Lee \& Rennie (1972).

Preparation of ovaries for light microscopy. Ovaries were excised from untreated animals on Days 28 and 30 of age, and from animals treated with hCG alone or in combination with a bolus of 10 i.u. hCG. Each ovary was immersed in Bouin's fixative at room temperature overnight, embedded in paraffin wax and sectioned at $5 \mu \mathrm{m}$. Photomicrographs were prepared after staining with haematoxylin and eosin.

Determination of follicular permeability. It is reasonable to expect that the extent of perfusion of individual follicles and the amount of ${ }^{125} \mathrm{I}$-labelled rat $\mathrm{LH}$ injected into each animal might differ significantly. To eliminate variance attributed to these factors, the amount of ${ }^{125} \mathrm{I}$-labelled rat $\mathrm{LH}$ in plasma and follicular fluid was expressed as a ratio of ${ }^{51} \mathrm{Cr}$, which is a freely-diffusible label. Animals were anaesthetized with pentobarbitone sodium (Nembutal; $2 \mathrm{mg}$ i.p.) and treated with $300 \mu \mathrm{Ci}^{51} \mathrm{Cr}$ in $80 \mu \mathrm{l}$ saline i.v. After $15 \mathrm{~min}, 150 \mu \mathrm{Ci}{ }^{125} \mathrm{I}$-labelled $\mathrm{LH}$ were injected into the same jugular vein. It was assumed that the concentration of ${ }^{51} \mathrm{Cr}$ was equivalent in the vascular and avascular compartments after this time. Ovaries from each animal were removed at different times after injection of ${ }^{125}$ I-labelled $\mathrm{LH}$; the right ovary always being removed before the left. The 5 largest follicles were dissected from each ovary, pooled, and hemisected in $200 \mu 10 \cdot 1 \%$ BSA-PBS. After centrifugation (Beckman microfuge-B, $15 \mathrm{sec}$ ) the supernatant containing follicular ${ }^{125} \mathrm{I}$ and ${ }^{51} \mathrm{Cr}$ activity was removed and an equal volume of trichloracetic acid (TCA; $10 \%$, w/v) was added. At the time of removal of each ovary, a matched blood sample was obtained from the vena cava. To $5 \mu$ l of this plasma $200 \mu 10 \cdot 1 \%$ BSA-PBS and $200 \mu$ TCA were added.

Total follicular and plasma ${ }^{125} \mathrm{I}$ and ${ }^{51} \mathrm{Cr}$ activities were determined on these preparations. Each was then centrifuged $\left(1600 \mathrm{~g}, 10 \mathrm{~min}, 4^{\circ} \mathrm{C}\right)$, the pellets washed twice in $1.0 \mathrm{ml}$ cold TCA and TCA-precipitable ${ }^{125} \mathrm{I}$ and residual ${ }^{51} \mathrm{Cr}$ activity were measured. Follicular and plasma TCAprecipitable ${ }^{125}$ I-labelled rat $\mathrm{LH}$ activity were expressed as concentrations rather than absolute values on the basis of ${ }^{51} \mathrm{Cr}$ activity in each preparation. Follicular permeability to ${ }^{125} \mathrm{I}$-labelled rat $\mathrm{LH}$ was then calculated as the ratio of the concentrations of TCA-precipitable LH activity in follicular fluid to that in plasma.

Measurement of ${ }^{125} \mathrm{I}$ and ${ }^{51} \mathrm{Cr}$ activity. The activities of ${ }^{125} \mathrm{I}$ and ${ }^{51} \mathrm{Cr}$ were determined simultaneously using a Packard 'Autogamma' scintillation spectrometer. Separate channels were used to determine the activity of each isotope. Whereas crossover from ${ }^{51} \mathrm{Cr}$ to ${ }^{125} \mathrm{I}$ was $9 \cdot 4 \%$, that of ${ }^{125} \mathrm{I}$ into the ${ }^{51} \mathrm{Cr}$ channel was $<1 \%$. All determinations were corrected for crossover between channels and for background.

Sodium dodecylsulphate-polyacrylamide gel electrophoresis (SDS-PAGE). SDS-PAGE was performed using $12.5 \%$ acrylamide gels in accordance with the method originally described by Hames (1981). Samples were diluted and in the case of TCA-precipitated material resolubilized in running buffer $(0.025 \mathrm{M}$-Tris, $0.192 \mathrm{M}$-glycine, $0.1 \%$ SDS) before application. A stacking gel of $4 \%$ acrylamide was used. Electrophoretic mobility of radioactivity as detected by fluorography was compared to that of radioiodinated trypsin inhibitor $(20000)$, carbonic anhydrase $(30000)$, ovalbumin (43000), albumin (67000) and phosphorylase B $(94000) .{ }^{51} \mathrm{Cr}$ was not administered in this instance. After staining with Coomassie blue, bands corresponding to unlabelled cytochrome $\mathrm{C}$ (13000), carbonic anhydrase (30000), ovalbumin (43000), catalase $(60000)$ and phosphorylase B $(94000)$ were also evident.

Immunoprecipitation of follicular fluid. To $200 \mu 10 \cdot 1 \%$ BSA-PBS containing follicular fluid from animals injected with ${ }^{125} \mathrm{I}$-labelled rat $\mathrm{LH}$, natural rabbit serum $(0.5 \mu \mathrm{l})$ goat anti-rabbit immunoglobulin $(5 \mu \mathrm{l})$ and rabbit anti-rat LH (NIDDKD ALH-7; 1,2 or $5 \mu \mathrm{l}$ ) were added and incubated overnight at $4^{\circ} \mathrm{C}$. After centrifugation $\left(2000 \mathrm{~g}, 30 \mathrm{~min}, 4^{\circ} \mathrm{C}\right)$ an aliquant of the supernatant fraction was subjected to SDS-PAGE. Marker proteins, trypsin inhibitor (20000), carbonic anhydrase 


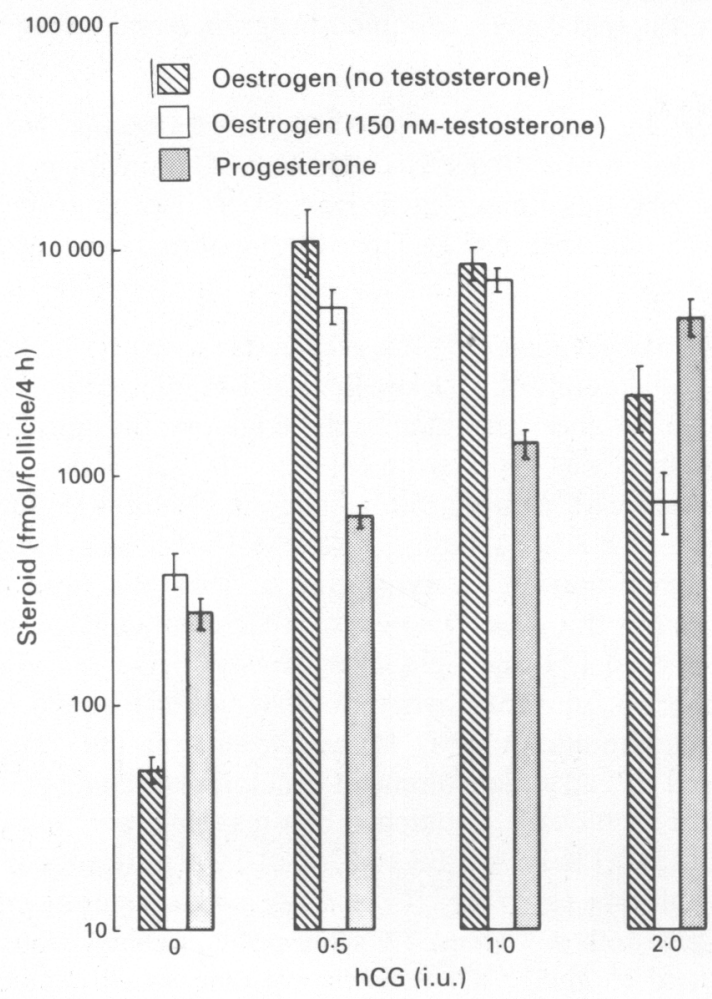

Fig. 4. Oestrogen and progesterone production by ovarian follicles in vitro after various doses of hCG in vivo. Follicles were isolated on Day 30 of age from untreated animals or animals treated with hCG on the morning and evening of Days 28 and 29 of age and were incubated in medium alone or in the presence of exogenous testosterone (150 nM). Each point represents the mean \pm s.e.m. of 20 individual follicles.

(30000), ovalbumin (45000) and albumin (67000) were run between lanes b and $\mathrm{c}$ and $\mathrm{c}$ and $\mathrm{d}$ and were visualized by staining with Coomassie blue.

Statistical analysis of data. Differences in steroid production at various intervals of hCG treatment and in response to each dose of hCG were compared by two-way analysis of variance and Duncan's multiple range test. At each time point or dose level, steroid production in the presence and absence of exogenous testosterone were compared using Student's $t$ test. Three-way analysis of variance was used to determine the significance of differences in permeability of follicles between treatment groups with time. Significantly different comparisons were claimed when $P$ was $<0 \cdot 05$.

\section{Results}

Light microscopy of ovaries

Ovaries isolated from untreated animals on Days 28 and 30 of age contained many pre-antral and small antral follicles, but were devoid of large antral follicles (Figs 1a, b). The ovaries of animals treated for 2 days with small doses of hCG contained large antral follicles in addition to 

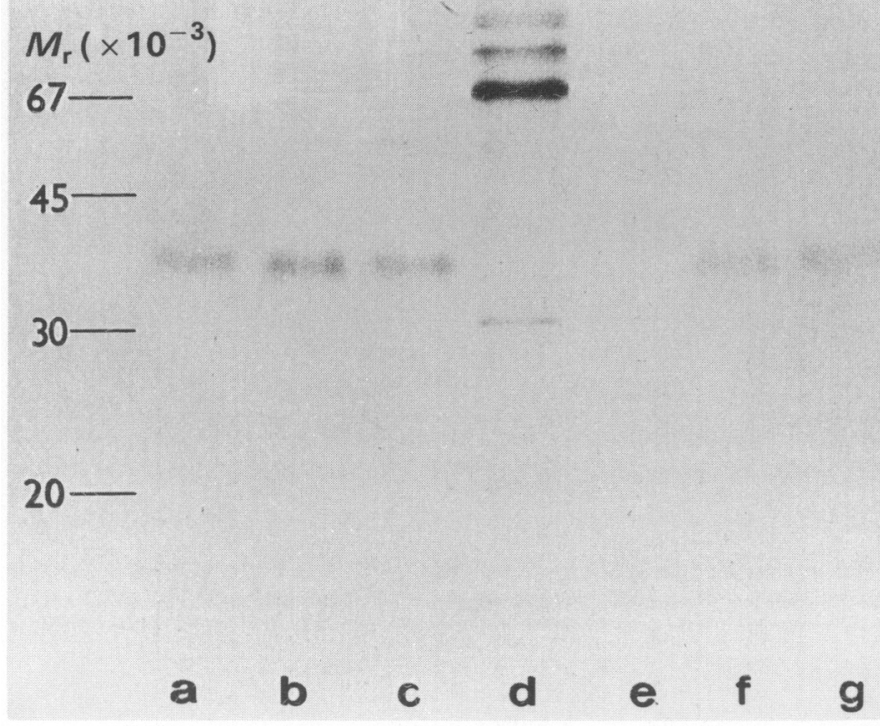

Fig. 5. Polyacrylamide electrophoresis of ${ }^{125} \mathrm{I}$-activity in plasma and follicular fluid of rats. Plasma and follicular fluid were obtained $10 \mathrm{~min}$ after injection of ${ }^{125} \mathrm{I}$-labelled $\mathrm{LH}$ into animals and subjected to SDS-PAGE with and without precipitation with TCA ('Materials and Methods'). Lane (a) follicular fluid; (b) TCA-insoluble material from follicular fluid; (c) ${ }^{125} \mathrm{I}$-labelled rat $\mathrm{LH}$ as injected; (d) ${ }^{125}$ I-labelled protein standards; (e) unlabelled protein standards; (f) plasma; (g) TCA-insoluble material from plasma.

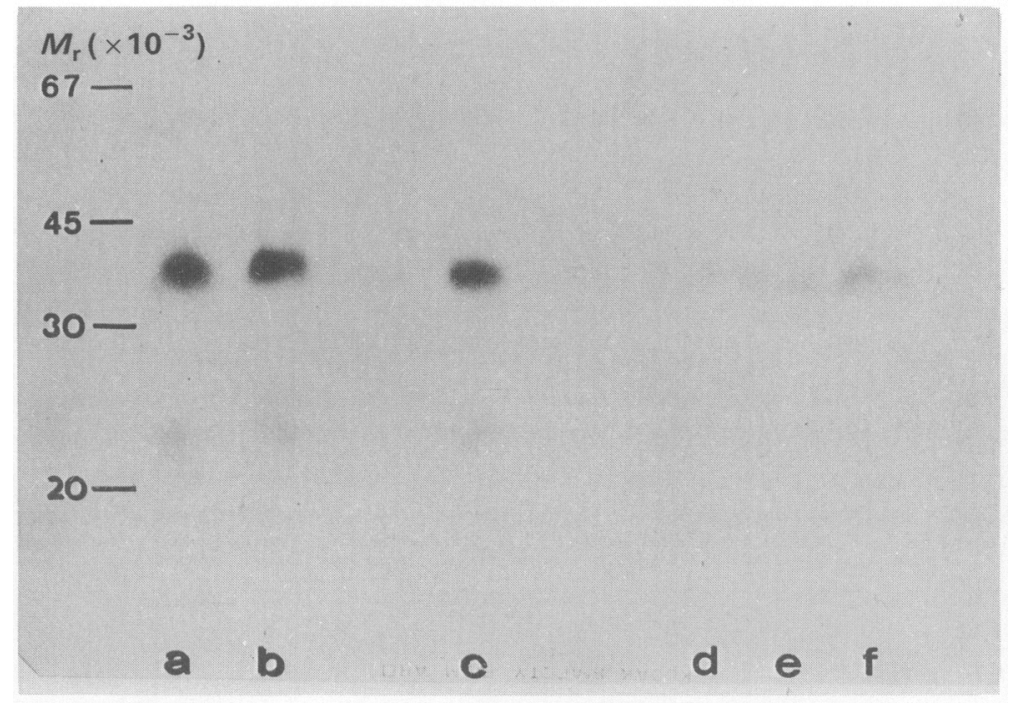

Fig. 6. Immunoprecipitation of follicular fluid. Follicular fluid was isolated $10 \mathrm{~min}$ after injection of ${ }^{125} \mathrm{I}$-labelled rat $\mathrm{LH}$ and subjected to SDS-PAGE after precipitation with TCA or anti-rat LH serum ('Materials and Methods') and fluorography. Lane (a) follicular fluid; (b) TCA-insoluble material from follicular fluid; (c) ${ }^{125} \mathrm{I}$-labelled rat $\mathrm{LH}$ injected; (d, e, f) follicular fluid precipitated with anti-rat LH serum $(\mathrm{d}, 4 \mu \mathrm{l} ; \mathrm{e}, 2 \mu \mathrm{l} ; \mathrm{f}, 1 \mu \mathrm{l})$. 


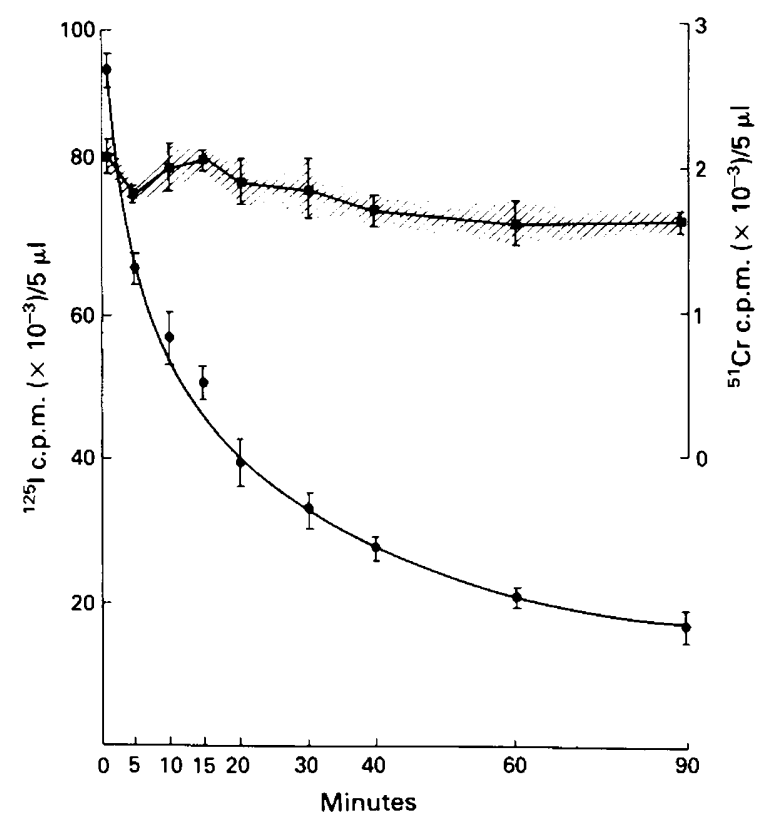

Fig. 7. Activity of ${ }^{5} 1^{1} \mathrm{Cr}$ and ${ }^{125} \mathrm{I}$-labelled rat $\mathrm{LH}$ in peripheral plasma. Five untreated animals (Day 30) were injected with ${ }^{51} \mathrm{Cr}(300 \mu \mathrm{Ci})$ at $t_{-15}$ and with ${ }^{125} \mathrm{I}$-labelled $\mathrm{LH}(150 \mu \mathrm{Ci})$ at $t_{0}$. Approximately $20 \mu \mathrm{l}$ blood was taken from the vena cava into a heparinized syringe at intervals from 1 to $90 \mathrm{~min}$ after injection of $\mathrm{LH}$. Total ${ }^{51} \mathrm{Cr}$ activity $(\boldsymbol{\square})$ was determined before TCA precipitation of $5 \mu \mathrm{l}$ plasma and ${ }^{125} \mathrm{I}$ activity $(\bullet)$ was determined in the TCA-insoluble fraction (see 'Materials and Methods'). Each point represents the mean \pm s.d. of 5 determinations.

numerous small antral and pre-antral follicles (Fig. 1c). By $4 \mathrm{~h}$ after an ovulatory dose of hCG, large antral follicles exhibiting early signs of luteinization were present. Corpora lutea were not observed (Fig. 1d).

\section{Steroid production by individual follicles in vitro}

Total oestrogen production by isolated follicles in the absence of exogenous testosterone increased from $51 \pm 7 \mathrm{fmol} /$ follicle $/ 4 \mathrm{~h}$ on the morning of Day 28 to a maximum of $24068 \pm$ $9542 \mathrm{fmol} /$ follicle $/ 4 \mathrm{~h}$ at $36 \mathrm{~h}$ exposure to hCG ( 3 injections, 0.5 i.u.) and declined thereafter (Fig. 2). Follicles isolated from animals after $12 \mathrm{~h}$ of treatment produced significantly more oestrogen in vitro at all times than did follicles isolated from untreated animals on Days 28 and 30 of age. Oestrogen production increased significantly after addition of exogenous testosterone (150 nM) to the incubation medium only in follicles isolated from untreated animals (Fig. 2).

Progesterone production by follicles isolated from untreated animals on Day 28 or Day 30 of age was $133 \pm 12$ and $118 \pm 6 \mathrm{fmol} / \mathrm{follicle} / 4 \mathrm{~h}$ respectively. This was increased significantly after exposure to hCG in vivo for $24-48 \mathrm{~h}$ and reached $1816 \pm 319 \mathrm{fmol} /$ follicle $/ 4 \mathrm{~h}$ at $48 \mathrm{~h}$ (Fig. 3).

Large antral follicles isolated $4 \mathrm{~h}$ after an ovulatory dose of hCG produced significantly less oestrogen (Fig. 1) and more progesterone (Fig. 3) than did large antral follicles isolated from animals treated with multiple small doses of hCG for $48 \mathrm{~h}$. Total oestrogen was reduced from $8120 \pm 1246$ to $4618 \pm 1266 \mathrm{nmol} /$ follicle $/ 4 \mathrm{~h}$ (data not shown) and progesterone was increased from $1816 \pm 319$ to $49899 \pm 4314$ fmol/follicle/4 h (Fig. 3). 


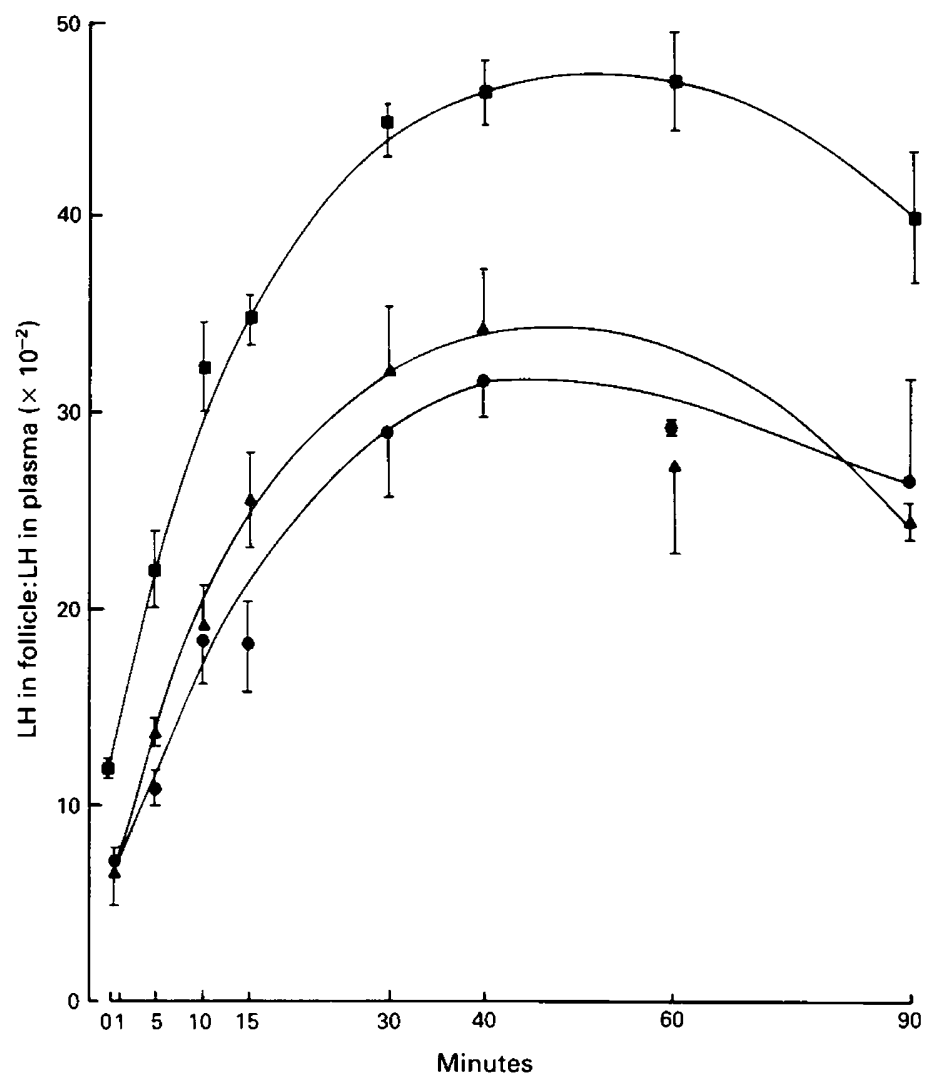

Fig. 8. Distribution of ${ }^{125} \mathrm{I}$-labelled rat $\mathrm{LH}$ between plasma and follicular fluid. Each point represents the mean ratio of ${ }^{125} \mathrm{I}$-labelled rat $\mathrm{LH}$ concentration in follicular fluid to that in plasma at each time point ( \pm s.e.m., 5 ovaries, 25 follicles). Small antral follicles (O), preovulatory follicles $(\Delta)$ and follicles isolated $4 \mathrm{~h}$ after exposure to an ovulatory dose of $\mathrm{hCG}$ in vivo $(10$ i.u., s.c.) (ם).

The steroidogenic response of follicles to hCG administration in vivo was dose-dependent. Oestrogen production by follicles isolated from animals treated for $48 \mathrm{~h}$ with $0.5,1.0$ or $2.0 \mathrm{i}$.u. hCG per dose were increased when compared to that produced by follicles isolated from untreated animals on Day 30 of age (Fig. 4). The amount of oestrogen produced in the absence of exogenous testosterone was greatest at doses of $0.5 \mathrm{i}$.u. hCG $(10667 \pm 3703 \mathrm{fmol} / \mathrm{follicle} / 4 \mathrm{~h})$ but was not significantly different from that produced at doses at 1.0 and $2.0 \mathrm{i}$.u. hCG. Only in the case of follicles isolated from untreated animals was oestrogen production significantly increased by addition of exogenous testosterone ( $150 \mathrm{nM}$ ) to incubation media. Progesterone production was significantly increased at the highest dose-level only (Fig. 4).

\section{SDS-PAGE and immunoprecipitation of ${ }^{125}$ I activity in plasma and follicular fluid}

After SDS-PAGE and fluorography of radioactive material in the injected preparation and samples of plasma and follicular fluid, a single band of radioactivity was observed at an $R_{\mathrm{f}}$ value approximating that of material of 34000 molecular weight. An identical band was evident in TCA-insoluble fractions of follicular fluid and plasma (Fig. 5). 


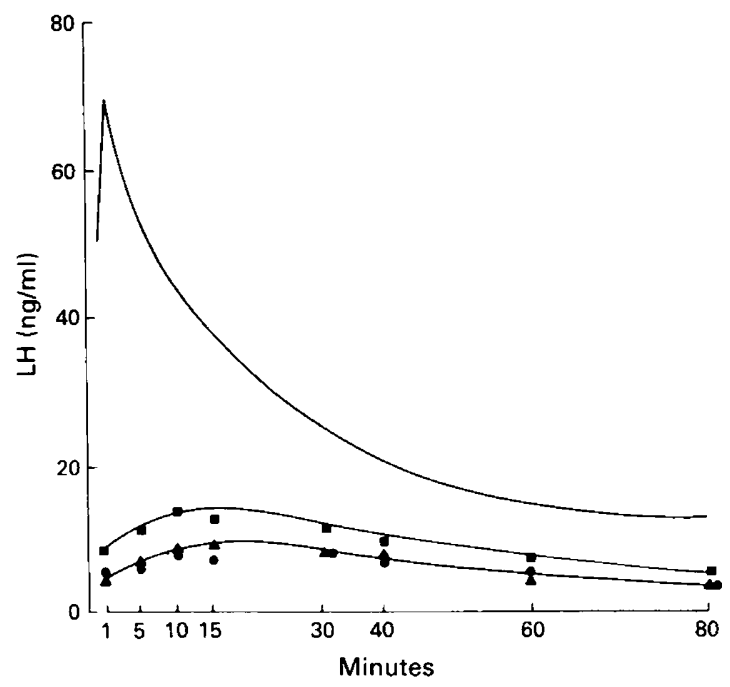

Fig. 9. Concentrations of $\mathrm{LH}$ in follicular fluid during an endogenous pulse of LH. The peak concentration of LH in plasma was assumed to be $70 \mathrm{ng} / \mathrm{ml}$. Using data obtained experimentally, the concentration of LH in plasma was first calculated. From these projected values, concentrations of $\mathrm{LH}$ in antral fluid of each follicle type were then calculated for times between 1 and $90 \mathrm{~min}$ on the basis of the distribution of ${ }^{125} \mathrm{I}$-labelled rat $\mathrm{LH}$ between plasma and follicular fluid (see Fig. 8).

Precipitation of radioactivity in follicular fluid with 1,2 or $5 \mathrm{ul}$ of an antiserum against rat $\mathrm{LH}$ reduced radioactivity in the band of $M_{\mathrm{r}} 34000$ to levels which were undetectable by fluorography (Fig. 6).

\section{${ }^{125} \mathrm{I}$ and ${ }^{51} \mathrm{Cr}$ activity in peripheral plasma}

The concentration of ${ }^{125} \mathrm{I}$-labelled rat $\mathrm{LH}$ in TCA precipitates of peripheral plasma reached $94353 \pm 3102$ c.p.m. $/ 5 \mu$ l by $1 \mathrm{~min}$ after injection and decayed exponentially thereafter $\left(t_{\frac{1}{2}}=15 \mathrm{~min}\right.$; Fig. 7). Concentrations of ${ }^{51} \mathrm{Cr}$ in peripheral plasma were relatively constant but decreased slightly from $2180 \pm 104$ c.p.m. $/ 5 \mu \mathrm{l}$ at $1 \mathrm{~min}$ to $1639 \pm 70$ at $90 \mathrm{~min}\left(16\right.$ and $105 \mathrm{~min}$ after ${ }^{51} \mathrm{Cr}$ injection respectively).

\section{Transfer of ${ }^{125}$ I-labelled rat LH from plasma into follicular fluid}

${ }^{125}$ I-labelled rat $\mathrm{LH}$ was detected in all follicles $1 \mathrm{~min}$ after injection. At no time was the relative concentration of ${ }^{125} \mathrm{I}$-labelled rat $\mathrm{LH}$ in small antral follicles significantly different from that in preovulatory follicles; maxima of $34 \cdot 2 \pm 3.0$ and $31 \cdot 7 \pm 2.0 \%$ of plasma ${ }^{125} \mathrm{I}$-labelled rat $\mathrm{LH}$ concentrations respectively were reached after $40 \mathrm{~min}$ (Fig. 8). Relative concentrations of ${ }^{125}{ }^{\text {I-labelled }}$ rat $\mathrm{LH}$ in preovulatory follicles exposed $4 \mathrm{~h}$ previously to an ovulatory dose of hCG were significantly greater $(P<0.05)$ than those in small antral and preovulatory follicles at all times examined; a maximum of $46 \cdot 2 \pm 1 \cdot 7 \%$ of ${ }^{125} \mathrm{I}$-labelled rat $\mathrm{LH}$ concentration in plasma was reached $\mathrm{l} h$ after injection of the labelled LH (Fig. 8).

\section{Antral volume as determined by follicular ${ }^{51}$ Cr activity}

Antral volume of isolated follicles was calculated from the total follicular ${ }^{51} \mathrm{Cr}$ activity and the concentration of ${ }^{51} \mathrm{Cr}$ in a matched sample of plasma. It was assumed that the concentration of ${ }^{51} \mathrm{Cr}$ in follicular fluid was identical to that in plasma at the time at which follicles were isolated. 
When determined by these means, significant $(P<0 \cdot 001)$ increases in follicular antrum volume were associated with hCG-induced follicular development and luteinization: $71 \pm 5 \mathrm{nl}$ (54 ovaries) for small antral follicles, $320 \pm 14 \mathrm{nl}$ (51 ovaries) for preovulatory follicles and $444 \pm 26 \mathrm{nl}$ (45 ovaries) for preovulatory follicles to hCG.

\section{Discussion}

These data indicate that transfer of $\mathrm{LH}$ from thecal capillaries to follicular fluid is limited in that concentrations of LH in follicular fluid never exceed more than half that in plasma at any time during a single exogenous pulse of hormone. Further, small antral and preovulatory follicles, which differ markedly in steroidogenic capacity, do not differ in their permeability to LH. Only after exposure to an ovulatory dose of hCG is permeability increased.

Increased permeability may be due to increased blood flow through follicular capillaries (Bruce \& Dimmitt, 1977) or increased permeability of capillary walls (Bassett, 1943; Burr \& Davies, 1951) and follicular basement membrane. Although the extent of the vascular network is much greater in preovulatory follicles of the rat (Bassett, 1943; Reynolds, 1973) and ewe (Hay \& Moor, 1975), these types of follicles did not differ in their permeability to LH. It is likely, therefore, that increased permeability of follicles results from alterations in the physical properties of capillary and follicular walls rather than increased vascularization.

Restriction of the entry of $\mathrm{LH}\left(M_{\mathrm{r}} 30000\right)$ into follicular fluid of small antral and preantral follicles not exposed to an ovulatory dose of hCG is inconsistent with earlier studies in which the concentrations of substances with molecular weights of up to $10^{6}$ were the same in follicular fluid and plasma (Shalgi, Kraicer, Rimon, Pinto \& Soferman 1973; Andersen, Kroll, Byskov \& Faber, 1976). The inference from these studies is that, on the basis of molecular weight alone, LH should equilibrate rapidly between blood and follicular fluid. The results of the present study in respect of $\mathrm{LH}$ indicate that this is not the case, the permeability of a substance is determined not only by molecular weight, but also the rate of diffusion into follicles and the temporal pattern of the presence of that substance in blood. Accordingly, if a substance is present at constant levels in blood, complete equilibration between blood and follicular fluid would inevitably be reached irrespective of molecular weight and rate of entry. In contrast, if this substance appeared in the circulation as a series of transient pulses, concentrations in follicular fluid might never equal those in plasma, plasma levels decaying before complete transfer to follicular fluid was possible. For example, concentrations of serum albumin $\left(M_{\mathrm{r}} 50000\right)$ in blood and follicular fluid are seen to be equal, but the concentration of $\mathrm{LH}\left(M_{\mathrm{r}} 30000\right)$ in follicular fluid never reaches that in plasma.

From the results of this study it is possible to calculate the intrafollicular concentrations of hormone which would result from an endogenous pulse of LH. Assuming each pulse of LH at dioestrus in female rats to have an amplitude of $70 \mathrm{ng}$ rLH-RP1/ml (Gallo, 1981a) intrafollicular concentrations in small antral and preovulatory follicles would be expected to reach $8 \mathrm{ng} / \mathrm{ml}$ by $10 \mathrm{~min}$ after the start of secretion (Fig. 9). Concentrations in preovulatory follicles exposed $4 \mathrm{~h}$ previously to an ovulatory dose of hCG would be expected to reach approximately twice the concentration $(14 \mathrm{ng} / \mathrm{ml})$ seen in other types of follicles at that time. A direct consequence of limited follicular permeability to $\mathrm{LH}$ is that changes in follicular concentrations of $\mathrm{LH}$ are much less labile than are those occurring in plasma and it is predicted that during a series of endogenous pulses, as would be observed in vivo, follicular concentrations of $\mathrm{LH}$ would remain relatively constant.

On this basis, it might be argued that the pulsatile pattern of gonadotrophin secretion in rats (Gallo, 1981a, b) is of little consequence to granulosa cell function. This is consistent with several experimental models whereby development of ovulatory follicles can be induced by relatively constant rather than pulsatile levels of exogenous hormones (Richards et al., 1976; Parker, Costoff, Muldoon \& Mahesh, 1976; Wright, Clarke \& Findlay, 1983) and suggests that the pulsatile nature 
of pituitary gonadotrophin secretion might not be of physiological significance to differentiation of granulosa cells and thus to follicular development. The acute increases in androstenedione and oestradiol concentrations in ovarian venous plasma of sheep which are associated with pulses of endogenous LH activity (Peckham \& Keikhofer, 1959) probably reflect increased thecal androgen production in response to $\mathrm{LH}$ and subsequent rapid diffusion of androgen into follicles (Falck, 1959; Dorrington, Moon \& Armstrong, 1975) rather than acute response of granulosa cells to each pulse of LH per se. For this reason, it cannot be stated with absolute certainty that the physiological significance of pulsatile gonadotrophin secretion is limited to interactions within the hypothalamo-hypophysial axis.

The experimental model used in the present study was based on the response of immature female rats to low, repeated doses of hCG (Richards \& Bogovich, 1982). Similar studies of adult rats at mid-pregnancy have been shown to result in preovulatory follicles that were functionally and morphologically indistinguishable from preovulatory follicles which develop in response to increased endogenous LH activity (Richards \& Kersey, 1979; Carson et al., 1981). Ovarian histology (Fig. 1), increased steroidogenic and aromatase activity in vitro (Figs 2-4) and increased antral volume confirm that large antral follicles developed in response to hCG administration and that these foilicles were preovulatory. These follicles responded to an ovulatory dose of hCG with decreased oestrogen and increased progesterone production in vitro, and showed morphological signs of granulosa cell luteinization. Because the 5 largest follicles only were dissected from each ovary, the data in respect of permeability of ovarian follicles to $\mathrm{LH}$ are considered representative of small antral, preovulatory and preovulatory follicles exposed to the preovulatory gonadotrophin surge.

Underlying assumptions in the manner in which radioisotopes have been used in this instance are that ${ }^{51} \mathrm{Cr}$ equilibrates rapidly with all extracellular fluids and that ${ }^{125} \mathrm{I}$ activity actually represents ${ }^{125}$ I-labelled rat $\mathrm{LH}$. The limited volume of antral fluid in rat follicles makes direct studies of equilibration of ${ }^{51} \mathrm{Cr}$ between plasma and follicular fluid technically difficult, if not impossible. However, considering the permeability of follicles to substances of low molecular weight (Shalgi et al., 1973; Andersen et al., 1976) and studies of the movement of radiolabelled water (Peckham \& Keikhofer, 1959) and sodium sulphate (Bostrom \& Odeblad, 1952) into follicles, radiolabelled chromate ions are expected to equilibrate between plasma and follicular fluid within minutes. Furthermore, because metabolism of $\mathrm{LH}$ by rat ovaries in vivo is minimal (Rorke, Faircloth \& Vaitukaitis, 1984) and the radioactivity in TCA-insoluble fractions of plasma and follicular fluid was measured selectively, it is reasonable to expect that the ${ }^{125}$ I-activity measured did in fact represent radiolabelled rat LH rather than metabolites of lower molecular weight. SDS-PAGE and immunoprecipitation confirmed that ${ }^{125} \mathrm{I}$-activity present in TCA-insoluble fractions was associated with material of a molecular weight of about 34000 .

We conclude that the entry of LH into small and large antral rat follicles is limited, and that exposure to an ovulatory dose of hCG results in a greater proportion of any given pulse of LH entering the antral fluid of follicles. The physiological significance, if any, of increased permeability to development and luteinization of follicles has yet to be determined.

This study was completed with the financial support of the National Health and Medical Research Council of Australia. We thank Dr R. J. Scaramuzzi and the WHO Matched Reagent Program for steroid antisera; Professor David de Kretser, Department of Anatomy, Monash University, for facilities for histology and photomicrography; and Diane Hollingsworth for typing the manuscript.

\section{References}

Andersen, M.M., Kroll, J., Byskov, A.G. \& Faber, M. (1976) Protein composition in the fluid of individual bovine follicles. J. Reprod. Fert. 48, 109-112.
Bassett, L.L. (1943) The changes in vascular pattern of the ovary of the albino rat during the estrous cycle. Am. J. Anat. 73, 251-280. 
Bostrom, H. \& Odeblad, E. (1952) Autoradiographic observations on the uptake of ${ }^{35} \mathrm{~S}$ in the genital organs of the female rat and rabbit after injection of labelled sodium sulphate. Acta endocr., Copenh. 10, 89-95.

Bruce, N.W. \& Dimmitt, S.B. (1977) Ovarian venous blood flow in non-pregnant and pregnant rats. $J$. Endocr. 72, 127-133.

Burger, H.G., Lee, V.W.K. \& Rennie, G.C. (1972) A generalised computer program for the treatment of data from competitive protein binding assays including radioimmunoassays. J. Lab. Clin. Med. 80, 302-312.

Burr, J.H. \& Davies, J.I. (1951) The vascular system of the rabbit ovary and its relationship to ovulation. Anat. Rec. 111, 273-290.

Carson, R.S., Richards, J.S. \& Kahn, L.E. (1981) Functional and morphological differentiation of theca and granulosa cells during pregnancy in the rat: dependence on increased basal luteinising hormone activity. Endocrinology 109, 1433-1441.

Dorrington, J.H., Moon, Y.S. \& Armstrong, D.T. (1975) Estradiol-17 $\beta$ biosynthesis in cultured granulosa cells of hypophysectomised immature rats; stimulation by follicle stimulating hormone. Endocrinology 77, 1328-1331.

Falck, B. (1959) Site of production of estrogen in the rat ovary as studied by microtransplants. Acta physiol. scand. 163 (Suppl. 47), 94-101.

Fraker, P.J. \& Speck, J.C., Jr (1978) Protein and cell membrane iodinations with a sparingly soluble chloroglycouril. Biochem. Biophys. Res. Commun. 80, 849-854.

Gallo, R.V. (1981a) Pulsatile LH release during the ovulatory LH surge on proestrus in the rat. Biol. Reprod. 24, 100-104.

Gallo, R.V. (1981b) Pulsatile LH release during periods of low level LH secretion in the rat estrous cycle. Biol. Reprod. 24, 771-777.

Goodman, R.L. \& Daniel, K. (1985) Modulation of luteinising hormone secretion by ovarian steroids in the rat. Biol. Reprod. 32, 217-225.

Hames, B.D. (1981) An introduction to polyacrylamide gel electrophoresis. In $\mathrm{Gel}$ Electrophoresis: $A$ Practical Approach, pp. 1-88. Eds B. D. Hames \& D. Rickwood. I.R.L. Press, Oxford.

Hay, M.F. \& Moor, R.M. (1975) Functional and structural relationships in the Graafian folicle population of the sheep ovary. J. Reprod. Fert. 45, 583-593.
Lindner, H.R., Amsterdam, A., Salomon, Y., Tsafriri, A., Nimrod, A., Lamprecht, S.A., Zor, U. \& Koch, Y. (1977) Intraovarian factors in ovulation: determinants of follicular response to gonadotrophins. $J$. Reprod. Fert. 51, 215-235.

Parker, C.R., Costoff, A., Muldoon, T.G. \& Mahesh, V.B. (1976) Actions of PMSG in the immature female rat: correlative changes in blood steroids, gonadotrophins and cytoplasmic estradiol receptors of the anterior pituitary and hypothalamus. Endocrinology 98, 129-138.

Peckham, B. \& Keikhofer, W. (1959) The movement of tritium-labeled water in the human ovarian follicle. Am. J. Obstet. Gynecol. 78, 1012-1019.

Reynolds, S.R.M. (1973) Blood and lymph vascular systems of the ovary. In Handbook of Physiology; Section 7, Vol. II, pt I, pp. 261-316. Ed. R. O. Greep. Am. Physiol. Soc., Washington D.C.

Richards, J.S. (1979) Hormonal control of ovarian follicular development: A perspective. Recent Prog. Horm. Res. 35, 343-373.

Richards, J.S. \& Bogovich, K. (1982) Effects of human chorionic gonadotropin and progesterone on follicular development in the immature rat. Endocrinology 111, 1429-1438.

Richards, J.S. \& Kersey, K.A. (1979) Changes in theca and granulosa cell function in antral follicles developing during pregnancy in the rat: gonadotropin receptors, cyclic AMP and estradiol-17ß. Biol. Reprod. 21, 1185-1201.

Richards, J.S., Ireland, J.J., Rao, M.C., Bernath, G.A., Midgley, A.R., Jr \& Reichert, L.E. (1976) Ovarian follicular development in the rat: Hormone receptor regulation by estradiol, follicle-stimulating hormone and luteinising hormone. Endocrinology 99, 1562-1570.

Rorke, E.A., Faircloth, G.T. \& Vaitukaitis, J.L. (1984) Metabolism of luteinising hormone by the pseudopregnant ovary. Endocrinology 115, 962-968.

Shalgi, R., Kraicer, P., Rimon, A., Pinto, M. \& Soferman, M. (1973) Proteins of human follicular fluid: the blood-follicle barrier. Fert. Steril. 24, 429-434.

Wright, P.J., Clarke, I.J. \& Findlay, J.K. (1983) The induction of fertile estrus in seasonally anoestrous ewes using a continuous low-dose administration of gonadotropin releasing hormone. Aust. vet. J. 60, $254-255$.

Received 16 July 1985 